\title{
Safety Performance Evaluation of a Three-Leg Unsignalized Intersection Using Traffic Conflict Analysis
}

\author{
Guoqiang Zhang, ${ }^{1,2,3}$ Jun Chen, ${ }^{1,2,3}$ and Jingya Zhao ${ }^{1,2,3}$ \\ ${ }^{1}$ Jiangsu Key Laboratory of Urban ITS, Southeast University, Nanjing 210096, China \\ ${ }^{2}$ Jiangsu Province Collaborative Innovation Center of Modern Urban Traffic Technologies, Southeast University, Nanjing 210096, China \\ ${ }^{3}$ School of Transportation, Southeast University, Nanjing 210096, China
}

Correspondence should be addressed to Guoqiang Zhang; guoqiang.zhang@163.com

Received 15 September 2016; Revised 18 December 2016; Accepted 16 January 2017; Published 23 April 2017

Academic Editor: Benoit Iung

Copyright ( 2017 Guoqiang Zhang et al. This is an open access article distributed under the Creative Commons Attribution License, which permits unrestricted use, distribution, and reproduction in any medium, provided the original work is properly cited.

Traffic conflicts were used to evaluate safety performance of a three-leg unsignalized intersection. With the aid of a video camera, data were collected at the intersection and 15-second time span was used in each observation to overcome the drawbacks of traditional methods of traffic conflict analysis. Time to collision (TTC), a widely accepted indicator, was used to identify whether an interaction between two vehicles was a traffic conflict. By using Poisson regression, a prediction model for traffic conflicts at the intersection was developed. Based upon the model, assuming that other factors remain constant, when time headway or speed of eastbound traffic on major road, which is crossed by left-turning traffic from minor road, increases, the number of traffic conflicts at the intersection decreases. When volume of left-turning traffic on minor road or speed of left-turning vehicles on minor road increases, the number of traffic conflicts at the intersection increases if other factors remain constant. Explanations for the influence of the factors, which were represented by independent variables of the prediction model, were then analyzed in detail.

\section{Introduction}

Compared with capacity analysis, safety performance evaluation is far more difficult, and, up to now, there are still no widely accepted standards as to how safety performance of all kinds of road facilities should be evaluated. This has led to the phenomenon that road facilities are planned and designed mainly based upon capacity analysis and safety is little considered partly because of the lack of suitable analysis tools $[1,2]$. Although traffic accidents are regarded as an effective index to evaluate safety performance, its drawbacks, such as rarity of traffic crashes and covering up in accident report, impair its feasibility and often make its applications very difficult $[3,4]$.

Studies showed that there was close relationship between traffic conflicts and traffic accidents $[5,6]$ and, as a result, traffic conflict analysis has been used to evaluate safety performance of various facilities $[7,8]$. Various methods were used to model relationship between traffic conflicts and all sorts of impacting factors such as traffic volumes, geometric designs, and traffic control devices, which partly explained some of the underlying causes of traffic conflicts [9-13]. Besides, microsimulation models were also developed to predict traffic conflicts, which were then used to evaluate safety performance [14-17].

Compared with segments, at-grade intersections are places where traffic conflicts occur with much more frequencies because of the rather complicated traffic situations [18]. This is especially the case for unsignalized intersections, where, without guidance of traffic signals, drivers have to choose the right time to pass the intersecting road all by themselves and the self-organizing traffic flows usually result in traffic conflicts $[19,20]$. Therefore, it is appropriate to study safety performance of unsignalized intersections using traffic conflict analysis, which is based upon data concerning traffic conflict.

In order to understand the mechanism of safety performance of unsignalized intersections, researches were carried 


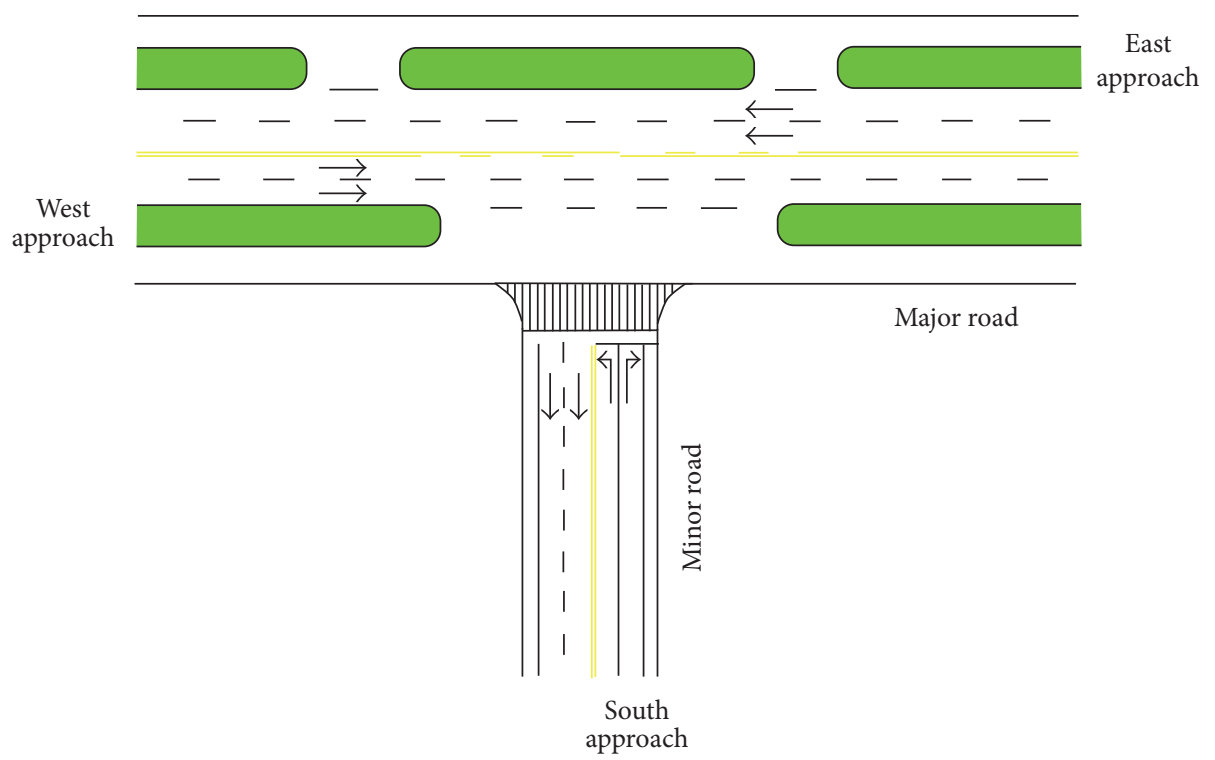

FIGURE 1: Geometric designs of the three-leg intersection.

out to study the relationship between traffic conflicts and impacting factors and meaningful conclusions were drawn as to how characteristics of traffic flows from different approaches impact traffic conflicts and safety of unsignalized intersections. These studies however were based upon aggregate data, which could not describe the exact characteristics of traffic conditions, when traffic conflicts occurred. For example, traffic flow rates are usually rather volatile and therefore the data for traffic volumes, which were aggregated over one or two hours, might have little relationship with the actual traffic situations which caused those traffic conflicts in just a few seconds.

Thus, the models and their conclusions, which were based on such aggregate data, were only appropriate to be used for analysis of such intersections where traffic demands were high and stable so that values of the variables in the models could reflect the actual situations under which traffic conflicts took place. For unsignalized intersections, traffic volumes are usually low and unstable and this is especially true for minor road approaches. As far as such intersections are concerned, the conventional methods of traffic conflict analysis are no longer appropriate.

In consideration of the deficiency discussed above, a new method of data collection for traffic conflict analysis, which was carried out by the aid of a video camera, was put forward. Instead of using data aggregated within hours, the method for traffic conflict analysis was based upon data recording events and indexes within 15 seconds. Using the method, safety performance of a three-leg unsignalized intersection was evaluated by analyzing traffic conflicts between vehicles on major road and turning vehicles from minor road.

\section{Data Collection}

The unsignalized intersection for the study was in the suburbs of Nanjing City, Jiangsu Province, which has a large population and lies in the east of China. It was a typical threeleg intersection with moderate traffic volumes on the major road and low traffic volumes on the minor road and volatility of the traffic volumes was so great. Its geometric designs were shown in Figure 1. The major road was a provincial trunk road with two lanes in each direction (eastbound direction or westbound direction), and the minor road, which was connected to the major road from the south, was a country road also with two lanes in each direction. Left-turning vehicles from minor road, which came from south approach, crossed the path of eastbound vehicles on major road, which came from west approach, and then merged with westbound vehicles on major road, which came from east approach.

Almost no vehicles on major road were observed to turn right or left and therefore traffic conflicts caused by turning vehicles from major road were not studied. Besides, traffic conflicts caused by right-turning vehicles from minor road were seldom observed because of the rather small flow rates of right-turning vehicles from minor road and the relatively easier performance of right-turning maneuvers. Thus, traffic conflicts caused by right-turning vehicles from minor road were not included in the analysis. Based upon reasons discussed above, the paper mainly focused on traffic conflicts between through vehicles on major road and leftturning vehicles from minor road.

It was also observed that there were very few pedestrians and bicyclists at the intersection. Therefore, influence of pedestrians and bicyclists was rather small and their influence was ignored in the study. In addition, westbound vehicles on major road were rarely in conflict with vehicles from minor road and their influence was also ignored.

Several safety indicators have been used to identify traffic conflicts and time to collision (TTC), a widely accepted indicator, was used in the paper. TTC is defined as the expected time for two vehicles to collide if they remain at their 
present speed and on the same trajectory. In the study, when TTC is no more than 2 seconds, the interactions between through vehicles on major road and left-turning vehicles from minor road were classified as traffic conflicts. Because sever traffic conflicts were rarely observed, they were not studied in the paper.

To facilitate data collection, a video camera was used to record vehicle movements at the intersection from the top of a high building in the vicinity. Later on, digital video files obtained from the field were played on the computer screen for many times to collect data such as traffic conflicts, vehicles types, time headway, and running speed. Whenever any evasive maneuvers were observed while left-turning vehicles from minor road were crossing the intersection, the corresponding part of the video files would be replayed several times to determine if such abnormal maneuvers were caused by conflict between through vehicles on major road and left-turning vehicles from minor road, and if so, location of the conflict point was also estimated, based upon which distance between the conflict point and the vehicle making evasive maneuvers was measured. And the distance was subsequently divided by speed of the vehicle before its evasive maneuvers to obtain TTC.

Theoretically speaking, the ideal method to study traffic conflicts microscopically is to use elementary units of exposure, which studies each encounter that may cause traffic conflicts and thus is able to explore contributing factors underlying traffic conflicts microscopically by analysis of individual events based upon a binomial model [21, 22]. However, the method assumes that vehicles arrive according to a Poisson process, which does not hold true in many circumstances where the arrival of vehicles lacks suitable randomness due to frequent appearance of platoons in the traffic stream. In the study, platoons of several vehicles were often observed on major road, and in such cases, leading vehicles influenced movements of following vehicles, which made the use of elementary units of exposure unsuitable. Therefore, in order to overcome the limitation, analysis of frequency of traffic conflicts within a given time span was applied by Poisson regression, which is able to explore impacting characteristics of platoons that may influence occurrence of traffic conflicts.

Most of the vehicle platoons lasted no more than 15 seconds, which was chosen as time span of each observation, whose frequency of traffic conflicts was used to develop a Poisson regression model. In all, 159 observations were obtained and 33 traffic conflicts were identified.

\section{Statistical Method}

Values of traffic conflicts within a short period of time are small nonnegative integers, so count data models should be used in the analysis. Among the various count data models, Poisson regression is by far the most popular one. The Poisson model assumes that the dependent variable is Poisson distribution. The Poisson distribution approximates rare-event count data. One requirement of the Poisson distribution is that the mean of count process equals its variance.
In a Poisson regression model, the probability that an unsignalized intersection experiences $y_{i}$ traffic conflicts during a fixed time period is given by

$$
p\left(y_{i}\right)=\frac{\mu_{i}^{y_{i}} e^{-\mu_{i}}}{y_{i} !}, \quad i=1,2,3, \ldots, n,
$$

where $\mu_{i}$ is the expected number of traffic conflicts for observation $i$ and $n$ is the number of observations.

Poisson models are estimated by specifying the Poisson parameter $\mu_{i}$ (the expected number of traffic conflicts) as a function of explanatory variables. The most common relationship between explanatory variables and the Poisson parameter is the log-linear model:

$$
\begin{aligned}
& \mu_{i}=\exp \left(\boldsymbol{\beta}^{\prime} \mathbf{x}_{i}\right) \\
& \boldsymbol{\beta}=\left(\beta_{0}, \beta_{1} x_{i 1}, \beta_{2} x_{i 2}, \ldots, \beta_{k} x_{i k}\right)^{\prime} \mathbf{x}_{i}=\left(x_{0}, x_{i 1}, x_{i 2}, \ldots, x_{i k}\right)^{\prime},
\end{aligned}
$$

where $x_{i l}(l=0,1,2, \ldots, k)$ are the explanatory variables for observation $i$ and $\beta_{i l}(l=0,1,2, \ldots, k)$ are the coefficients for the explanatory variables.

This model is estimable by standard maximum likelihood methods. Maximum likelihood estimates produce Poisson parameters that are consistent, asymptotically normal, and asymptotically efficient. The likelihood function is given as

$$
L(\boldsymbol{\beta})=\sum_{i} \frac{\exp \left[-\exp \left(\boldsymbol{\beta}^{\prime} \mathbf{x}_{i}\right)\right]\left[\exp \left(\boldsymbol{\beta}^{\prime} \mathbf{x}_{i}\right)\right]^{y_{i}}}{y_{i} !} .
$$

To facilitate the process of manipulation and estimation, the $\log$ of the likelihood function is used and it is written as

$$
\operatorname{LL}(\boldsymbol{\beta})=\sum_{i=1}^{n}\left[-\exp \left(\boldsymbol{\beta}^{\prime} \mathbf{x}_{i}\right)+y_{i} \boldsymbol{\beta}^{\prime} \mathbf{x}_{i}-\ln \left(y_{i} !\right)\right] .
$$

As with most statistical models, the estimated parameters can be used to make inferences about how influential factors impact traffic conflicts, which in turn will help us to understand safety performance of an unsignalized intersection under various situations.

\section{Data Analysis Results}

In the study, a prediction model for traffic conflicts was developed to explore various factors that impact safety performance and contribute to traffic conflicts at the selected three-leg unsignalized intersection. The dependent variable of the model is the total number of traffic conflicts identified at the selected intersection within each 15 -second interval. Eight independent variables were initially considered. The descriptive statistics of these variables are given in Table 1.

Stepwise regression method was used to choose appropriate independent variables in the Poisson model. The regression results are given in Table 2. Four variables were found to be statistically insignificant and were excluded from the model. The best model has four independent variables. The independent variables include the time headway of eastbound traffic on major road, the volume of left-turning 
TABLE 1: Descriptive statistics of variables for model development.

\begin{tabular}{|c|c|c|c|c|c|}
\hline Variables & Min & Max & Mean & Standard deviation & Observations \\
\hline $\begin{array}{l}\text { Number of traffic conflicts (conflicts/15 } \\
\text { seconds) }\end{array}$ & 0 & 2 & 0.21 & 0.45 & 159 \\
\hline $\begin{array}{l}\text { Eastbound traffic volumes on major } \\
\text { road (vehicles/15 seconds) }\end{array}$ & 1 & 8 & 2.46 & 1.37 & 159 \\
\hline $\begin{array}{l}\text { Volume of left-turning traffic on minor } \\
\text { road (vehicles/15 seconds) }\end{array}$ & 1 & 6 & 1.6 & 0.98 & 159 \\
\hline $\begin{array}{l}\text { Time headway of eastbound traffic on } \\
\text { major road (seconds) }\end{array}$ & 0.24 & 36.94 & 9.14 & 7.18 & 159 \\
\hline Percentage of trucks on major road (\%) & 0 & 1 & 0.31 & 0.35 & 159 \\
\hline $\begin{array}{l}\text { Percentage of trucks on minor road } \\
(\%)\end{array}$ & 0 & 1 & 0.09 & 0.28 & 159 \\
\hline $\begin{array}{l}\text { Speed of eastbound vehicles on major } \\
\text { road ( } \mathrm{km} / \text { hour })\end{array}$ & 20.4 & 78.46 & 46.99 & 10.89 & 159 \\
\hline $\begin{array}{l}\text { Speed of left-turning vehicles on } \\
\text { minor road (km/hour) }\end{array}$ & 1.1 & 21.79 & 11.25 & 4.45 & 159 \\
\hline $\begin{array}{l}\text { Trajectory of left-turning vehicles from } \\
\text { minor road }\end{array}$ & - & - & - & - & 159 \\
\hline 1 (normal) & - & - & - & - & 85 (53.5\%) \\
\hline 0 (abnormally curved) & - & - & - & - & $74(46.5 \%)$ \\
\hline
\end{tabular}

-: not applicable.

TABLE 2: Poisson regression model for prediction of traffic conflicts.

\begin{tabular}{lcccc}
\hline Variable & Coefficient & $\begin{array}{c}\text { Standard } \\
\text { error }\end{array}$ & $z$ & $p>|z|$ \\
\hline $\begin{array}{l}\text { Time headway of } \\
\text { eastbound traffic on major }\end{array}$ & -0.091 & 0.035 & -2.640 & 0.008 \\
$\begin{array}{l}\text { road } \\
\text { Volume of left-turning }\end{array}$ & 0.283 & 0.145 & 1.950 & 0.051 \\
traffic on minor road & & & & \\
$\begin{array}{l}\text { Speed of eastbound } \\
\text { vehicles on major road }\end{array}$ & -0.103 & 0.021 & -4.910 & 0.000 \\
$\begin{array}{l}\text { Speed of left-turning } \\
\text { vehicles on minor road }\end{array}$ & 0.114 & 0.044 & 2.580 & 0.010 \\
Constant & 1.466 & 1.141 & 1.290 & 0.199 \\
$\begin{array}{l}\text { Log likelihood } \\
\text { LR } \chi^{2}(4)\end{array}$ & -61.577 & & & \\
Prob $>\chi^{2}$ & 50.78 & & & \\
Pseudo $R^{2}$ & 0.000 & & & \\
\hline
\end{tabular}

traffic on minor road, the speed of eastbound vehicles on major road, and the speed of left-turning vehicles on minor road. The expected number of traffic conflicts for a specific scenario from the Poisson regression is expressed by

$$
\begin{aligned}
Y= & \exp \left(1.466-0.091 X_{1}+0.283 X_{2}-0.103 X_{3}\right. \\
& \left.+0.114 X_{4}\right),
\end{aligned}
$$

where $Y$ is expected number of traffic conflicts for a specific scenario (conflicts/15 seconds); $X_{1}$ is time headway of eastbound traffic on major road (seconds); $X_{2}$ is volume of left-turning traffic on minor road (vehicles/15 seconds); $X_{3}$ is speed of eastbound vehicles on major road ( $\mathrm{km} /$ hour); and $X_{4}$ is speed of left-turning vehicles on minor road ( $\mathrm{km} /$ hour).

The coefficient for time headway of eastbound traffic on major road is very significant with $p$ value equal to 0.008 . The value of the coefficient is negative, indicating that traffic conflicts at the intersection will increase with the decrease of time headway of eastbound traffic on major road assuming that all other factors remain constant. This is in agreement with conclusions of published papers that more traffic volumes lead to more accidents and traffic conflicts. Time headway is the reciprocal of traffic volume and, therefore, more eastbound traffic volume on major road leads to decrease of time headway of eastbound traffic. This means that there is less opportunity for drivers of left-turning vehicles from minor road to select a gap in the conflicting traffic flow, which is large enough for them to cross the major road safely. Under more stressful situations, drivers may behave more aggressively and thus cause more traffic conflicts.

The coefficient for volume of left-turning traffic on minor road is significant with $p$ value equal to 0.051 . The positive value of the coefficient means that increase of volume of leftturning traffic on minor road will lead to more traffic conflicts at the intersection if other factors remain constant. This is easy to understand. Left-turning vehicles on major road are in potential conflict with through vehicles on major road and their increase will obviously lead to more traffic conflicts.

The coefficient for speed of eastbound vehicles on major road is extremely significant with $p$ value equal to 0.000 . The negative value of the coefficient indicates that the number of traffic conflicts at the intersection decreases with the increase of speed of eastbound vehicles on major road. This may be explained by the psychological phenomenon that drivers of 
left-turning vehicles from minor road may become cautious out of concern for their own safety when they are confronted with faster speed of eastbound vehicles on major road. This in turn will lead to more safe driving behavior and cause the decrease of the number of traffic conflicts.

The coefficient for speed of left-turning vehicles on minor road is also extremely significant with $p$ value equal to 0.000 . The value of the coefficient is, however, positive, indicating that the number of traffic conflicts at the intersection increases with the increase of speed of left-turning vehicles on minor road. While driving at a higher speed, drivers of left-turning vehicles on minor road are faced with far more stressful situations if they happen to be in conflict with through vehicles on major road, which may cause the number of traffic conflicts to increase. Besides, this phenomenon might also be explained by the relationship between speed of left-turning vehicles on minor road and risky behavior of drivers of these vehicles. According to the law on road traffic safety, drivers of left-turning vehicles should decelerate or stop before reaching the conflict point to yield the rightof-way to through vehicles on major road. Therefore, it is expected that left-turning vehicles should have slow speed when they approach the major road and thus higher speed of left-turning vehicles on minor road might be related to more aggressive driving behaviors of the drivers of those vehicles, whose riskier behaviors could bring more traffic conflicts.

With the prediction model for traffic conflicts, safety performance of the three-leg unsignalized intersection can be evaluated and analyzed. For example, if other factors remain constant, a one-unit increase in time headway of eastbound traffic on major road will result in $1-\exp (-0.091)=8.70 \%$ fewer traffic conflicts at the unsignalized intersection, and a one-unit increase in volume of left-turning traffic on minor road will result in $\exp (0.283)-1=32.71 \%$ more traffic conflicts at the unsignalized intersection. Similarly, assuming that all other factors remain constant, a one-unit increase in speed of eastbound vehicles on major road will result in $1-\exp (-0.103)=9.79 \%$ fewer traffic conflicts at the unsignalized intersection, and a one-unit increase in speed of left-turning vehicles on minor road will result in $\exp (0.114)-$ $1=12.08 \%$ more traffic conflicts at the unsignalized intersection.

\section{Discussions}

The aim of this study is to evaluate safety performance of a three-leg unsignalized intersection by analyzing traffic conflicts between different traffic flows at the intersection. With the assistance of a video camera, the research team collected traffic conflicts and many other related data. In order to better understand what causes traffic conflicts to occur during a very short time, time span of 15 seconds was used in each observation, which is quite different from the time spans used by conventional methods of conflict analysis. Time to collision (TTC), a widely accepted indicator, was used to identify whether an interaction between two vehicles is a traffic conflict.

By using Poisson regression, a prediction model for traffic conflicts was developed to evaluate safety performance of the unsignalized intersection under various situations. Eight independent variables were initially considered. The best model has four independent variables and they include the time headway of eastbound traffic on major road, the volume of left-turning traffic on minor road, the speed of eastbound vehicles on major road, and the speed of left-turning vehicles on minor road.

The model can be applied in analysis of safety performance of the unsignalized intersection. Based upon the model, assuming that other factors remain constant, when time headway of eastbound traffic on major road or speed of eastbound vehicles on major road increases, the number of traffic conflicts at the intersection decreases. Nevertheless, when volume of left-turning traffic on minor road or speed of left-turning vehicles on minor road increases, the number of traffic conflicts at the intersection increases if other factors remain constant. Explanations for the influence of the factors were analyzed in detail. In addition, the model was also used to specify quantitatively safety impacts of the various factors. Examples were given as to how traffic conflicts at the intersection will change due to one-unit increase of an independent variable.

\section{Conclusions}

Safety performance of a three-leg unsignalized intersection was analyzed by using traffic conflict analysis. A prediction model was developed to evaluate expected number of traffic conflicts within 15 seconds. The study provided some quantified results regarding impacts of some influencing factors upon safety performance of unsignalized intersections. The method in this paper can be used as a reference when similar researches are to be carried out in the future.

Eight independent variables were initially considered. And although four variables were found to be statistically insignificant and were excluded from the model, this did not mean that the excluded variables had nothing to do with traffic conflicts. For example, abnormal trajectory of leftturning vehicles from minor road was found to be in greater danger of experiencing a traffic conflict. Besides, trucks were found to be involved in traffic conflicts more frequently than cars. Further researches can be carried out to explore impacts of those excluded factors. Other factors such as geometry designs, weather conditions, road surface conditions, and visibility should also be explored in further researches.

The following limitations shall be considered when similar researches are to be carried out in the future. Firstly, the sample size was small, and, as a result, reliability of the model was not analyzed by using independent sample(s). Secondly, severe traffic conflicts were not analyzed because of scarcity of data. Thirdly, 2 seconds was used as the TTC indicator for traffic conflicts and was slightly higher than 1.5 seconds, which is widely used. Selecting a relevant "high" threshold value might lead to a biased evaluation.

\section{Conflicts of Interest}

The authors declare that there are no conflicts of interests regarding the publication of this paper. 


\section{Acknowledgments}

This research was jointly supported by the General Project of National Natural Science Foundation of China (Grant no. 51278103) and the Key Project of National Natural Science Foundation of China (Grant no. 51638004). Their assistance is greatly appreciated.

\section{References}

[1] AASHTO, A Policy on Geometric Design of Highways and Streets, 2001.

[2] Transportation Research Board, Highway Capacity Manual, TRB, Washington, DC, USA, 2010.

[3] L. Yuan, H.-W. Yuan, Y.-F. Ma, and Y.-W. Ren, "Development of a safety evaluation model for provincial highway," Discrete Dynamics in Nature and Society, vol. 2014, Article ID 394846, 10 pages, 2014.

[4] Transportation Research Board, Guidance for Implementation of the AASHTO Strategic Highway Safety Plan: A Guide for Addressing Unsignalized Intersection Collisions, vol. 5, Washington, DC, USA, 2003.

[5] M. J. Williams, "Validity of the traffic conflicts technique," Accident Analysis and Prevention, vol. 13, no. 2, pp. 133-145, 1981.

[6] P. Edara, S. Breslow, C. Sun, and B. R. Claros, "Empirical evaluation of J-turn intersection performance analysis of conflict measures and crashes," Transportation Research Record, vol. 2486, pp. 11-18, 2015.

[7] M. R. Parker and C. V. Zegeer, "Traffic conflict technique for safety and operations observers manual," Tech. Rep. FHWA-IP88-027, FHWA, Washington, DC, USA, 1989.

[8] U. Shahdah, F. Saccomanno, and B. Persaud, "Integrated traffic conflict model for estimating crash modification factors," Accident Analysis and Prevention, vol. 71, pp. 228-235, 2014.

[9] Transportation Research Board, Review of International Practices Used to Evaluate Unsignalized Intersections, Washington, DC, USA, 1997.

[10] A. C. Lorion and B. Persaud, "Investigation of surrogate measures for safety assessment of urban two-way stop controlled intersections," Canadian Journal of Civil Engineering, vol. 42, no. 12, pp. 987-992, 2015.

[11] W. Cheng, N. Zhang, W. Li, and J. Xi, "Modeling and application of pedestrian safety conflict index at signalized intersections," Discrete Dynamics in Nature and Society, vol. 2014, Article ID 314207, 6 pages, 2014.

[12] W. K. M. Alhajyaseen, "The integration of conflict probability and severity for the safety assessment of intersections," Arabian Journal for Science and Engineering, vol. 40, no. 2, pp. 421-430, 2014.

[13] K. El-Basyouny and T. Sayed, "Safety performance functions using traffic conflicts," Safety Science, vol. 51, no. 1, pp. 160-164, 2013.

[14] C. Wang and N. Stamatiadis, "Evaluation of a simulation-based surrogate safety metric," Accident Analysis and Prevention, vol. 71, pp. 82-92, 2014.

[15] R. Fan, H. Yu, P. Liu, and W. Wang, "Using VISSIM simulation model and surrogate safety assessment model for estimating field measured traffic conflicts at freeway merge areas," IET Intelligent Transport Systems, vol. 7, no. 1, pp. 68-77, 2013.

[16] C. Caliendo and M. Guida, "Microsimulation approach for predicting crashes at unsignalized intersections using traffic conflicts," Journal of Transportation Engineering, vol. 138, no. 12, pp. 1453-1467, 2012.

[17] G. Zhang and J. Lu, "Study on unsignalized access points using microscopic traffic simulation," in Proceedings of the 7th International Conference on Traffic and Transportation Studies, (ICTTS 2010), pp. 990-998, Kunming, China, August 2010.

[18] J. J. Lu, S. Chen, X. Ge, and F. Pan, "A programmable calculation procedure for number of traffic conflict points at highway intersections," Journal of Advanced Transportation, vol. 47, no. 8, pp. 692-703, 2013.

[19] I. A. Kaysi and A. S. Abbany, "Modeling aggressive driver behavior at unsignalized intersections," Accident Analysis and Prevention, vol. 39, no. 4, pp. 671-678, 2007.

[20] H. Li, Z. Tian, and W. Deng, "Capacity of multilane all-way stopcontrolled intersections based on the conflict technique," Transportation Research Record, no. 2257, pp. 111-120, 2011.

[21] H. Summala, "Accident risk and driver behaviour," Safety Science, vol. 22, no. 1-3, pp. 103-117, 1996.

[22] R. Elvik, A. Erke, and P. Christensen, "Elementary units of exposure," Transportation Research Record, no. 2103, pp. 25-31, 2009. 


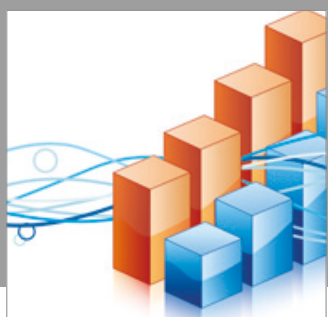

Advances in

Operations Research

vatersals

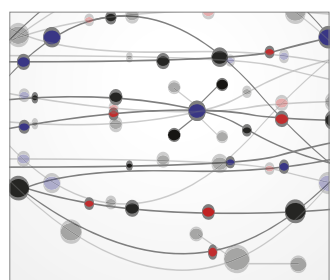

\section{The Scientific} World Journal
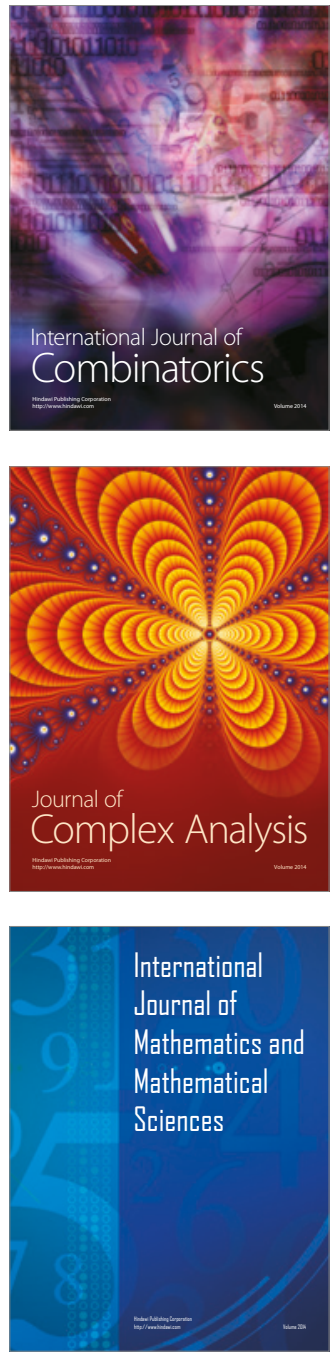
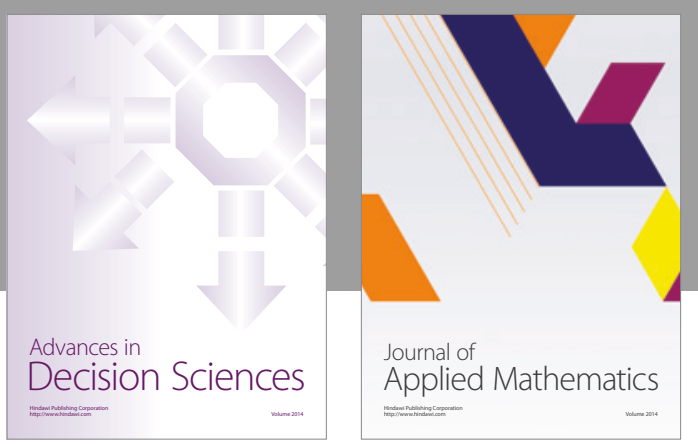

Algebra

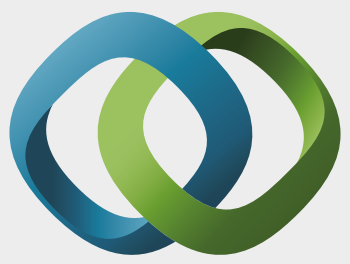

\section{Hindawi}

Submit your manuscripts at

https://www.hindawi.com
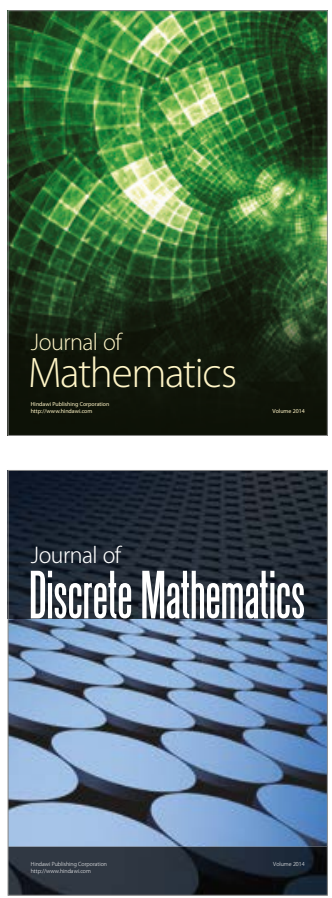

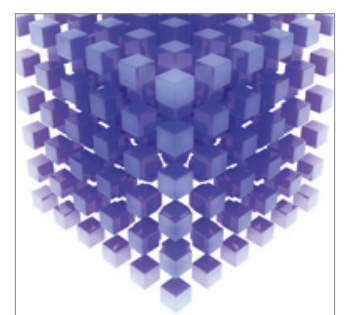

Mathematical Problems in Engineering
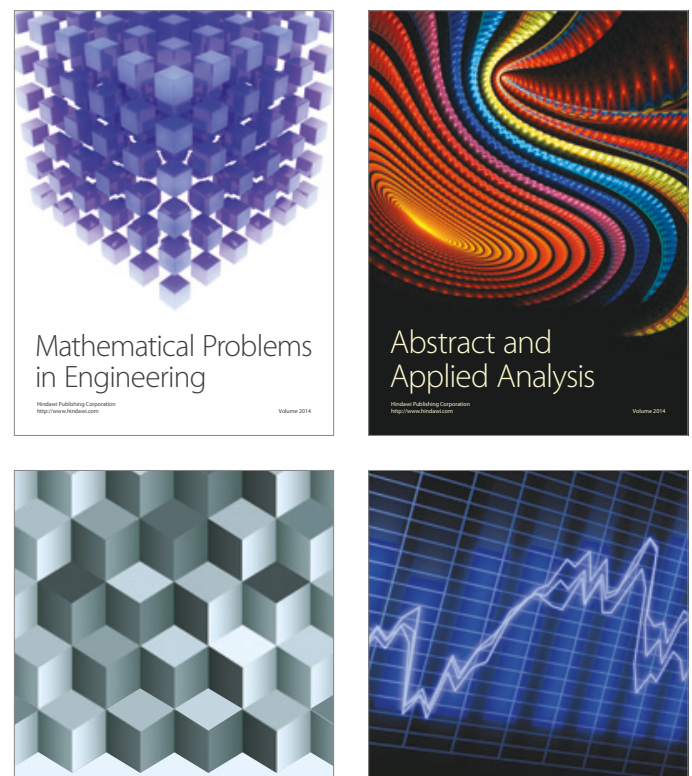

Journal of

Function Spaces

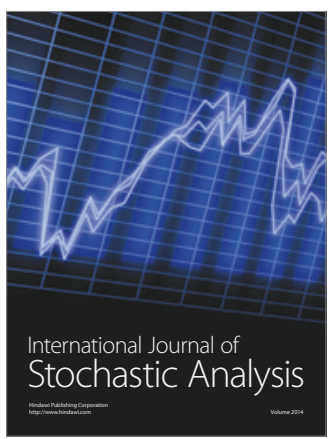

Probability and Statistics
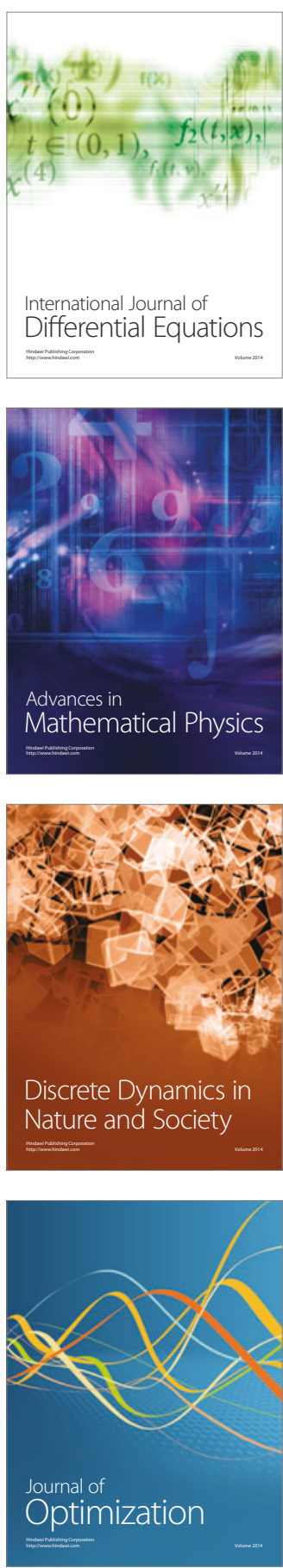